\title{
Agrobacterium-mediated genetic transformation of Chinese chestnut (Castanea mollissima Blume)
}

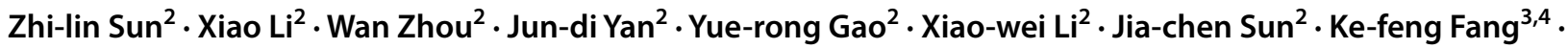 \\ Qing Zhang ${ }^{2} \cdot$ Yu Xing ${ }^{1,2} \cdot$ Ling Qin ${ }^{1,2} \cdot$ Qing-qin Cao ${ }^{1,2}$
}

Received: 18 June 2019 / Accepted: 3 October 2019 / Published online: 7 November 2019

(c) The Author(s) 2019

\begin{abstract}
Chinese chestnut (Castanea mollissima) is an important germplasm resource for the breeding of Castanea species worldwide with vital ecological and economic value. Biotechnology overcomes the limitations of traditional breeding and accelerates germplasm improvement. However, a genetic transformation system for Chinese chestnut has not yet been established. In this study, a stable and efficient Agrobacterium-mediated genetic transformation method for Chinese chestnut is described. Embryogenic calli of $C$. mollissima cv. 'Yanshanhongli' were used as the target material. The sensitivity of embryogenic calli to kanamycin was determined, whereby the proliferation of non-transformed calli was completely inhibited at $180 \mathrm{mg} / \mathrm{L}$. Antibiotic inhibition results for Chinese chestnut embryogenic calli showed that $50 \mathrm{mg} / \mathrm{L}$ cefotaxime and $500 \mu \mathrm{M}$ timentin completely inhibited the growth of Agrobacterium tumefaciens but did not affect the normal growth of Chinese chestnut embryogenic calli. When embryogenic calli were co-cultured for 2 days with Agrobacterium tumefaciens strain AGL1 harboring the PBI121-EGFP plasmid, an embryogenic callus transformation efficiency of $4.55 \%$ was obtained, and two transgenic chimera were acquired. This Agrobacterium-mediated transformation system for Chinese chestnut provides a fundamental platform for genetic improvement of core germplasm and for further verification of gene function.
\end{abstract}

\section{Key message}

A method of Agrobacterium-mediated transformation was established for Chinese chestnut, providing a basis for genetic improvement of core germplasm and an important platform for further verification of gene function in Chinese chestnut.

Keywords Chinese chestnut $\cdot$ Somatic embryo $\cdot$ Regeneration $\cdot$ Agrobacterium-mediated transformation

Abbreviations
WPM $\quad$ McCown's Woody Plant Medium salts
2,4-D
6-BA

Communicated by Wenwu Guo.

Electronic supplementary material The online version of this article (https://doi.org/10.1007/s11240-019-01713-4) contains supplementary material, which is available to authorized users.

Zhi-lin Sun, Xiao Li and Wan Zhou have contributed equally to this work.

Ling Qin

qinlingbua@126.com

Qing-qin Cao caoqingqin@bua.edu.cn

Extended author information available on the last page of the article
EGFP Enhanced green fluorescent protein

RT-PCR Reverse transcription-polymerase chain reaction

CTAB Cetyltriethylammnonium bromide

nptII Neomycin phosphotransferase II gene

E1 Embryo initiation medium

E2 Embryo development medium

E3 Embryo maturation medium

E4 Embryo germination medium

\section{Introduction}

Chinese chestnut (Castanea mollissima) has important ecological functions and economic value, and its production ranks first in the world of nut production (FAOSTAT Statistics Database 2017. http://www.fao.org/faostat/en/\#home). Chinese chestnut has become an important resource for 
chestnut breeding worldwide due to its strong pest and disease resistance and environmental adaptability, and it occupies an important position among Castanea spp. (Hebard 2006; Miller et al. 2014).

Transgenic regeneration systems can overcome the limitations of traditional breeding and accelerate germplasm improvement. Agrobacterium-mediated methods are convenient for acquiring transgenic plants of many species, such as Quercus robur (Vidal et al. 2010), willow (Liu et al. 2015), cotton (Chen et al. 2014), white ash (Palla et al. 2015), tomato (Chetty et al. 2013), sugarcane (Mayavan et al. 2013), and sorghum (Wu and Zhao 2017).

Among the genus Castanea, both European chestnut (C. sativa) and American chestnut ( $C$. dentata) have been genetically transformed using Agrobacterium (Maynard et al. 2015; Corredoira et al. 2004, 2007). European chestnut was the first transgenic Castanea species obtained by Agrobacterium infection worldwide (Seabra and Pais 1998). The first transgenic attempt in American chestnut was in 1994, though only transgenic callus was obtained through microprojectile bombardment (Merkle et al. 1994). By 2006, American chestnut had successfully been transformed with Agrobacterium (Polin et al. 2006). The choice of explant for both American chestnut and European chestnut dramatically influenced the transformation efficiency. For example, the transformation efficiency in European chestnut reached $30 \%$ when globular embryos were used, which was higher than that of cotyledon-shaped embryos (6.7\%) (Corredoira et al. 2007). In addition, GUS expression of resistant colonies can reach 100\% in American chestnut when using proembryogenic masses from different lines (Andrade et al. 2009). Different Agrobacterium strains also influenced the transformation efficiency of Castanea genetic transformation. For European chestnut, the EHA105 strain resulted in a higher transformation efficiency (25\%) than the C58C1 strain (1.9\%) (Corredoira et al. 2004). Both EHA105 and AGL1 led to the production of transgenic shoots of American chestnut (Polin et al. 2006; Andrade et al. 2009; Zhang et al. 2011; Newhouse et al. 2014), though comparison of the transformation efficiency of these two strains was not mentioned.

Disease-resistant germplasm materials of Castanea have been obtained by transgenic technology. Overexpression of the European chestnut thaumatin-like protein gene (CsTLI) in somatic embryogenic lines of European chestnut resulted in a certain tolerance to ink disease (Corredoira et al. 2012). American chestnut expressing a wheat oxalate oxidase gene through Agrobacterium co-transformation caused resistance to blight disease, which was inherited by the next generation (Newhouse et al. 2014). Although somatic embryo regeneration of Chinese chestnut was successfully established in a previous study (Lu et al. 2017), genetic transformation of Chinese chestnut has not been reported.
In this study, embryogenic calli of Chinese chestnut were used to establish a genetic transformation system through Agrobacterium-mediated technology, providing a basis for the genetic improvement of core germplasm and further verification of gene function in Chinese chestnut.

\section{Materials and methods}

\section{Plant materials and culture conditions}

Embryogenic calli initiated from the tips of immature embryos of C. mollissima 'Yanshanhongli' (Lu et al. 2017) were used in this study. These embryogenic calli were maintained by secondary embryogenesis with sequential subculture at 3-week intervals on Embryo initiation medium (E1) consisting of $2.3 \mathrm{~g} / \mathrm{L}$ McCown's Woody Plant Medium salts (WPM) (Phyto Tech, U.S.A) (Lloyd and Mccown 1980), $109 \mathrm{mg} / \mathrm{L}$ Nitsch and Nitschvitamins (Phyto Tech, U.S.A) (Nitsch and Nitsch 1969), $1 \mathrm{~g} / \mathrm{L}$ casein (Phyto Tech, U.S.A), $3 \%$ sucrose (w/v), $0.3 \%$ phytagel (w/v) (Phyto Tech, U.S.A), $1.8 \mu \mathrm{M}$ 2,4-D (Sigma, U.S.A), and $1.1 \mu \mathrm{M}$ 6-BA (Sigma, U.S.A). Before autoclaving at $121^{\circ} \mathrm{C}$ for $21 \mathrm{~min}$, the $\mathrm{pH}$ of the medium was adjusted to 5.5 (Merkle et al. 1991). These embryogenic calli were cultivated in the dark at approximately $23-25^{\circ} \mathrm{C}$ for $1-2$ weeks since their last subculture and then used for transformation experiments as well as for testing explant sensitivity to kanamycin, cefotaxime and timentin.

\section{Agrobacterium strains and plasmid}

In this study, two Agrobacterium tumefaciens strains and one plasmid were used. The strains were AGL1 (Lazo et al. 1991), and GV3101, both carrying the plasmid pBI121 (Fig. S1), which contains a neomycin phosphor transferase II (nptII) selectable marker and an enhanced green fluorescent protein $(E G F P)$ reporter gene driven by the cauliflower mosaic virus (CaMV 35S) promoter. Positive colonies were grown in the dark for approximately 2 days at $28{ }^{\circ} \mathrm{C}$ in liquid LB medium (Sambrook et al. 1989) containing $50 \mathrm{mg} / \mathrm{L}$ kanamycin and $50 \mathrm{mg} / \mathrm{L}$ rifampicin on a rotary shaker $(220 \mathrm{rpm})$. One milliliter of bacterial suspension was inoculated into $100 \mathrm{~mL}$ of liquid LB selection medium and incubated at $28{ }^{\circ} \mathrm{C}(220 \mathrm{rpm})$ until the OD 600 reached $0.8-1.2$. Fifty milliliters of the bacterial suspension were centrifuged at 3,500 rpm for $15 \mathrm{~min}$. The supernatant was removed, and $20 \mathrm{~mL}$ of Vir induction medium (Polin et al. 2006), which contains WPM basal salts, $1 \%$ sucrose and $9.75 \mathrm{~g} / \mathrm{L}$ 2-(N-morpholino) ethanesulfonic acid (MES) and $100 \mathrm{mM}$ filter-sterilized acetosyringone. The sample was vortexed to resuspend the pellet and then incubated at 
20-22 ${ }^{\circ} \mathrm{C}(75 \mathrm{rpm})$ on a shaker for 3-4 h (Maynard et al. 2015).

\section{Co-cultivation period}

The infected embryogenic calli were transferred to sterile filter paper until the calli were almost dry. Then, the calli were transferred to an empty dish containing desiccation sterile filter paper. They were placed in $\sim 5 \mathrm{~mm}$ diameter piles with $\sim 1 \mathrm{~cm}$ between the piles. $200 \mu \mathrm{L}$ sterile water was added to the sterile filter paper to maintain the humidity in the dish. These calli were co-cultivated for 2 or 3 days in the dark at $23-25{ }^{\circ} \mathrm{C}$. Thereafter, these calli were transferred to Agrobacterium Kill Medium, which contains $50 \mathrm{mg} / \mathrm{L}$ cefotaxime and $500 \mu \mathrm{M}$ timentin in E1, incubated for 7 days at $23-25^{\circ} \mathrm{C}$ in the dark (Maynard et al. 2015). At the end of the screening stage, the resistant callus regeneration rate was recorded to determine the optimal co-culture time. Transformation efficiency was assessed by EGFP signal intensity.

\section{Screening of antibiotic combinations and sensitivity of embryogenic calli to antibacterial antibiotics}

Cefotaxime was added to E1 at three concentrations of 50, 100 , and $200 \mathrm{mg} / \mathrm{L}$, as well as timentin at three concentrations of 400,500 , and $600 \mu \mathrm{M}$. A total of 11 treatments were performed, and no antibiotic was used as a control (Table 1). $18 \mu \mathrm{L}$ bacterial liquid was inoculated into E1 containing antibiotic combinations of each treatment. The antibacterial effect was observed after 5 days' incubation in the dark at $28{ }^{\circ} \mathrm{C}$. Treatments with low antibiotic

Table 1 The inhibitory effect of antibacterial antibiotic combinations on Agrobacterium

\begin{tabular}{llll}
\hline Treatments & \multicolumn{2}{l}{ Antibiotic concentrations } & $\begin{array}{l}\text { Anti- } \\
\text { bacterial } \\
\text { effect }\end{array}$ \\
\cline { 2 - 3 } $\begin{array}{l}\text { Cefotaxime } \\
(\mathrm{mg} / \mathrm{L})\end{array}$ & Timentin $(\mu \mathrm{M})$ & \\
\hline 1 & 50 & 400 & + \\
2 & 50 & 500 & ++ \\
3 & 50 & 600 & ++ \\
4 & 100 & 400 & ++ \\
5 & 100 & 500 & ++ \\
6 & 100 & 600 & ++ \\
7 & 200 & 400 & ++ \\
8 & 200 & 500 & ++ \\
9 & 200 & 600 & ++ \\
10 & 0 & 700 & ++ \\
11 & 300 & 0 & ++ \\
Control & 0 & 0 & - \\
\hline
\end{tabular}

'-' means no antibacterial effect; '+' means not completely antibacterial effect, and plaque is opaque; ' ++ ' means completely antibacterial effect and plaque is transparent concentrations were selected. Three replicates were set for each treatment.

Subsequently, the effect of antibiotic combinations on the growth of embryogenic calli was analyzed. $0.1 \mathrm{~g}$ embryogenic calli were inoculated into E1 containing selected antibiotics combinations for 1-2 weeks. Three replicates were set for each treatment. The fresh weight of callus clumps was evaluated to determine the optimal antibiotic combination.

\section{Sensitivity of embryogenic calli to kanamycin}

To determine embryogenic callus sensitivity to kanamycin, embryogenic callus clumps were inoculated into E1 ( $\mathrm{Lu}$ et al. 2017) supplemented with different levels of kanamy$\operatorname{cin}(0,30,60,90,120,150,180$ and $210 \mathrm{mg} / \mathrm{L})$. Kanamycin was dissolved in sterile, deionized water, filter-sterilized $(0.22 \mu \mathrm{m})$, and added to the E1 after it was autoclaved. Four petri dishes were used for each treatment, and each dish contained 18 embryogenic callus clumps. Three replicates were set for each treatment. After the embryogenic callus clumps were incubated for 35 days, the numbers of secondary callus clumps were recorded to calculate the callus proliferation rate.

\section{Transformation procedures}

Fifteen clumps (approximately $3 \mathrm{~g}$ ) of vigorous embryogenic calli incubated in E1 for 1-2 weeks were transferred to a $15 \mathrm{~mL}$ centrifuge tube containing $5 \mathrm{~mL}$ Agrobacterium inoculum until the clumps were submerged. Then these clumps were incubated for $1 \mathrm{~h}$ at room temperature on a $360^{\circ}$ rotating shaker (30-40 rpm). The co-cultivation protocol was described in section 'Co-cultivation period'. Embryogenic callus clumps were then transferred to selection medium which was supplemented with $180 \mathrm{mg} / \mathrm{L}$ kanamycin in Agrobacterium Kill Medium for 6-8 weeks at 2-week intervals (Maynard et al. 2015). Resistant embryogenic callus clumps were selected.

\section{Plant regeneration of transgenic somatic embryos}

The resistant embryogenic calli were transferred to E1, E2, and E3 in order, all containing $180 \mathrm{mg} / \mathrm{L}$ kanamycin, incubated in the dark at $23-25^{\circ} \mathrm{C}$ until cotyledonary embryos appeared. All of the cotyledonary embryos were transferred to $\mathrm{E} 4$ and incubated under a $16-\mathrm{h} / 8$-h light/dark photoperiod at $23-25{ }^{\circ} \mathrm{C}$ according to the description of $\mathrm{Lu}$ et al. (2017). Subculture was performed with fresh medium every 2 weeks until a new shoot formed. 


\section{Visualization of GFP}

After 3 weeks of incubation in E1 with kanamycin, kanamycin-resistant embryogenic calli with GFP fluorescence were detected using a fluorescence stereomicroscope (ZEISS SteREO Discovery. V20, Germany) equipped with a 488-nm excitation channel. GFP-positive somatic embryos were isolated and subcultured on selection medium with kanamycin to proliferate and establish different embryogenic transgenic lines.

\section{DNA isolation and PCR amplification}

Total genomic DNA of GFP-positive calli was extracted using a modified cetyltrimethylammonium bromide (CTAB) method (Cheng et al. 2005). The quality of purified total DNA was observed by $1.0 \%(\mathrm{w} / \mathrm{v})$ agarose gel electrophoresis, and the concentration was determined by a UV-Vis Spectrophotometer (Scan Drop, Germany). The final concentration of isolated total DNA was diluted to $50 \mathrm{ng} / \mu \mathrm{L}$ and stored at $-20{ }^{\circ} \mathrm{C}$ for further use. The presence of the transgenes EGFP and nptII was confirmed by PCR analysis. PCR reactions were carried out in a $10 \mu \mathrm{L}$ volume containing $1 \times$ Taq buffer, $0.4 \mu \mathrm{L}$ of dNTPs $(10 \mathrm{mM}), 0.5 \mu \mathrm{L}$ of each primer $(10 \mu \mathrm{M}), 0.1 \mu \mathrm{L}$ of Taq DNA polymerase $(5 \mathrm{U} / \mu \mathrm{L}$, TaKaRa) and 20-50 ng of genomic DNA. The specific primers were shown as follow: forward 5'-GTGGTCAGTCCC TTATGGTG-3' and reverse 5'-TTACTTGTACAGCTCGTC CATG-3' for EGFP; forward 5'-ATGATTGAACAAGAT GGATTGCA-3' and reverse 5'-GAACTCGTCAAGAAG GCGATAGA-3' for $n p t I I$. The expected sizes of amplicons for EGFP and $n p t I I$ were $740 \mathrm{bp}$ and $761 \mathrm{bp}$, respectively. Amplifications were performed using the following program: $95^{\circ} \mathrm{C}$ for $5 \mathrm{~min}, 36$ cycles at $95{ }^{\circ} \mathrm{C}$ for $30 \mathrm{~s}, E G F P$ $\left(56^{\circ} \mathrm{C}\right) /$ nptII $\left(57^{\circ} \mathrm{C}\right)$ for $30 \mathrm{~s}$ and $72{ }^{\circ} \mathrm{C}$ for $45 \mathrm{~s}$, and $72{ }^{\circ} \mathrm{C}$ for $10 \mathrm{~min}$. The amplified products were assessed by $1.0 \%$ (w/v) agarose gel electrophoresis and visualized using a Gel imager (Bio RAD, U.S.A.).

\section{RNA isolation and PCR analysis}

Total RNA was extracted using Plant RNA Kit (Omega, U.S.A.) based on the manufacturer's recommendations. To remove any remaining DNA, each RNA sample was digested with DNase I (Takara, Japan). cDNA was synthesized using M-MLV reverse transcriptase (Invitrogen, U.S.A.). The obtained cDNA was stored at $-20{ }^{\circ} \mathrm{C}$ for PCR analysis. Reactions were carried out in a total volume of $10 \mu \mathrm{L}$ containing $1 \times$ Taq buffer, $0.4 \mu \mathrm{L}$ of dNTPs $(10 \mathrm{mM}), 0.5 \mu \mathrm{L}$ of each primer $(10 \mu \mathrm{M}), 0.1 \mu \mathrm{L}$ of Taq DNA polymerase $(5 \mathrm{U} /$ $\mu \mathrm{L}$, TaKaRa) and $1 \mu \mathrm{L}$ of cDNA. The specific primers for the $E G F P$ gene, amplification program, PCR product isolation and visualization were as described above.

\section{Statistical analysis}

Data were recorded using Excel 2013. All of the experiments were conducted in at least three replicates. Statistical analysis was performed using analysis of variance (ANOVA). Significant differences were determined by Duncan's multiple range tests at the 5\% level using SPSS17.0.

\section{Results}

\section{Determination of the optimum concentration of kanamycin}

The proliferation rate of embryogenic calli was analyzed 35 days after inoculation on E1 supplemented with different concentrations of kanamycin. As kanamycin concentration increased, the callus proliferation rate gradually decreased with significant differences $(\mathrm{P}<0.05)$ (Fig. 1). The proliferation of embryogenic callus completely stopped when the kanamycin concentration reached $180 \mathrm{mg} / \mathrm{L}$. Therefore we determined $180 \mathrm{mg} / \mathrm{L}$ to be the optimum concentration and used it in E1, E2, E3, and E4 as our selection agent.

\section{Effect of concentration of antibacterial antibiotics on the growth of embryogenic calli}

As shown in Table 1, ten combinations completely inhibited the growth of Agrobacterium, and four of those with relatively low concentration of antibiotics were selected to further compare the effect on callus growth. The combination of $50 \mathrm{mg} / \mathrm{L}$ cefotaxime and $500 \mu \mathrm{M}$ timentin did not inhibit the growth of embryogenic calli compared with the other

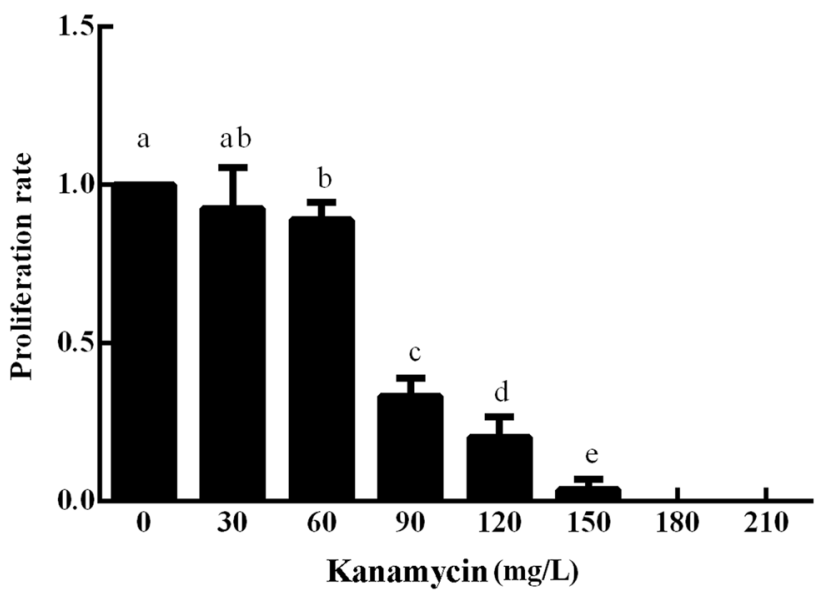

Fig. 1 Effect of kanamycin on the proliferation rate of embryogenic callus of Chinese chestnut. Callus proliferation rate is the ratio of secondary callus clumps to initial callus clumps. Treatments with different letters indicate statistical significance at $\alpha=0.05$ 
three combinations, which indicating that this combination of antibiotics had no toxicity on somatic embryo growth (Fig. 2). Therefore, we determined $50 \mathrm{mg} / \mathrm{L}$ cefotaxime and $500 \mu \mathrm{M}$ timentin to be the optimal concentrations and used them in Agrobacterium Kill Medium.

\section{Effect of Agrobacterium strains and co-cultivation period on the transformation efficiency}

After 8 weeks of culture in selective medium, we screened 65 clumps of kanamycin-resistant calli from the 641 callus clumps initially cultured (Table 2). As shown in Table 2, the regeneration rate of resistant callus after 2 days of co-culture was significantly higher than that of 3 days. The transformation efficiency using AGL1 after 2 days' co-culture was $4.55 \%$, which showed a significant difference $(\mathrm{P}<0.05)$ in

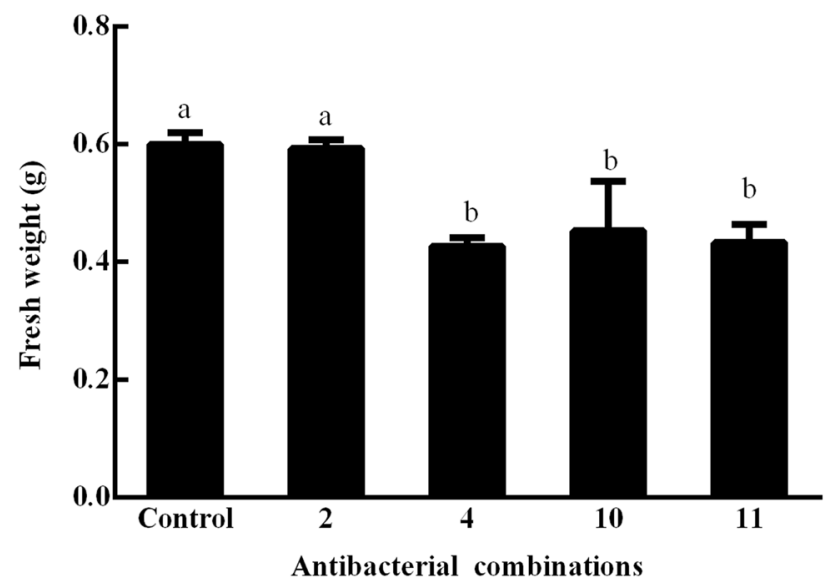

Fig. 2 Effect of antibacterial antibiotics on the fresh weight of embryogenic callus of Chinese chestnut. Control represents no antibiotics, 2 represents the group of $50 \mathrm{mg} / \mathrm{L}$ cefotaxime and $500 \mu \mathrm{M}$ timentin, 4 represents the group of $100 \mathrm{mg} / \mathrm{L}$ cefotaxime and $400 \mu \mathrm{M}$ timentin, 10 represents $700 \mu \mathrm{M}$ timentin, and 11 represents $300 \mathrm{mg} / \mathrm{L}$ cefotaxime. Treatments with different letters indicate statistical significance at $\alpha=0.05$ comparison with the other treatments. The AGL1 strain resulted in a higher transformation efficiency of the Chinese chestnut than the GV3101 strain, and 2 days of co-culture with Agrobacterium was suitable for the genetic transformation of Chinese chestnut embryogenic callus.

\section{Selection of kanamycin-resistant embryogenic calli and regeneration of somatic embryos}

The screening of resistant embryogenic calli was the most critical step in the genetic transformation process. In this experiment, embryogenic calli were cultured in E1 selection medium as shown in Fig. 3. After 6-8 weeks of culture, nonresistant calli became dark brown, but the resistant calli were white. The resistant calli were cultivated and proliferated on E1 plus kanamycin. As shown in Fig. 4c, d, the transgenic somatic embryos were screened out after 2 months culture on E2 plus kanamycin. Figure $4 \mathrm{e}-\mathrm{h}$ depicts that the transgenic cotyledonary embryos are formed after 4 months of selection. The transformed somatic embryo clumps exhibited green fluorescence under UV light excitation, indicating that the EGFP gene had been transferred and integrated into the somatic embryo genome. Finally, two chimeric transgenic shoots were obtained. As presented in Fig. 4k, 1, the transgenic shoots produced green fluorescence signals, whereas non-transgenic shoots did not (Fig. 4i, j).

\section{Molecular identification of transgenic lines of Chinese chestnut}

Seven clumps of transgenic calli were selected randomly and confirmed by PCR. As shown in Fig. 5, the positive control and transgenic lines produced specific target bands for EGFP and nptII. While the corresponding fragments were not amplified using the negative control and water samples. Therefore, we presumed that EGFP and nptII had been transferred into the genome of resistant calli. Green fluorescence signals in leaves (Fig. $4 \mathrm{k}, \mathrm{l}$ ) and the target bands

Table 2 Effect of co-cultivation time on genetic transformation of embryogenic callus of Chinese chestnut

\begin{tabular}{lllllll}
\hline Groups & $\begin{array}{l}\text { Number of cal- } \\
\text { lus clumps }\end{array}$ & $\begin{array}{l}\text { Number of } \\
\text { resistant callus }\end{array}$ & $\begin{array}{l}\text { Number of callus } \\
\text { with GFP signal }\end{array}$ & $\begin{array}{l}\text { Regeneration rate of } \\
\text { resistant callus }{ }^{\mathrm{a}}(\%)\end{array}$ & $\begin{array}{l}\text { Transformation } \\
\text { efficiency }(\%)\end{array}$ & $\begin{array}{l}\text { Number of } \\
\text { shoots with GFP } \\
\text { signal }\end{array}$ \\
\hline GV3101-2 days & 155 & 31 & 3 & $20.0 \pm 2.2 \mathrm{a}$ & $1.94 \pm 0.11 \mathrm{~b}$ & 0 \\
AGL1-2 days & 176 & 11 & 8 & $6.25 \pm 3.6 \mathrm{bc}$ & $4.55 \pm 0.42 \mathrm{a}$ & 2 \\
GV3101-3 days & 162 & 17 & 3 & $10.5 \pm 4.8 \mathrm{~b}$ & $1.85 \pm 0.06 \mathrm{~b}$ & 0 \\
AGL1-3 days & 188 & 6 & 4 & $3.19 \pm 4.2 \mathrm{c}$ & $2.13 \pm 0.84 \mathrm{~b}$ & 0 \\
Total & 641 & 65 & 16 & & 2 \\
\hline
\end{tabular}

Treatments with different letters indicate statistical significance at $\alpha=0.05$

${ }^{\text {a }}$ Regeneration rate of resistant callus is the ratio of resistant callus clumps to initial callus clumps

${ }^{\mathrm{b}}$ Transformation efficiency is the ratio of callus clumps with GFP signal to initial callus clumps 


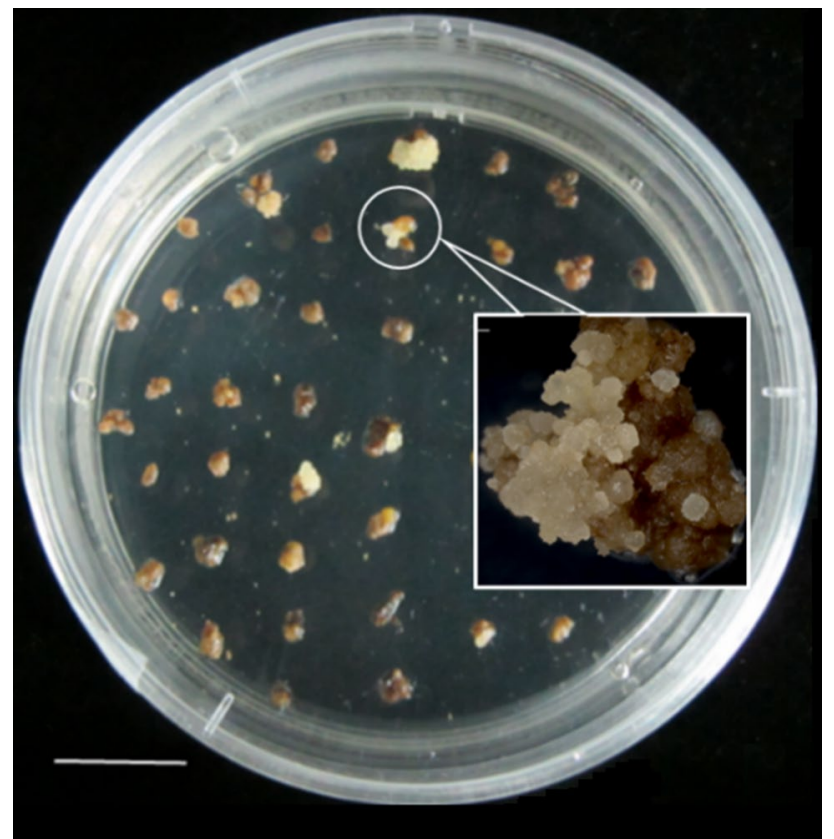

Fig. 3 Selection of resistant embryogenic callus of Chinese chestnut on solid medium. Bar is $1 \mathrm{~cm}$

(Fig. 6) indicated the expression of EGFP in these two chimeric transgenic shoots.

\section{Discussion}

The yield of Chinese chestnut ranks the highest among the world's chestnut production. Due to its wide adaptability and high tolerance to biotic and abiotic stresses, growers can reduce the use of pesticides and save costs. Chinese chestnut also has ecological value, as it can be planted in mountain land to save cultivated land and prevent soil erosion. Growers eagerly expect for excellent cultivars possessing improved traits. Genetic transformation is a powerful tool for the genetic improvement of plants, and it has been successfully applied to many woody plants, such as European chestnut, American chestnut, apple and grape (Seabra and Pais 1998; Yepes et al. 1994; Andrade et al. 2009; Sabbadini et al. 2019). In this study, precise genetic transformation of Chinese chestnut was established, which will benefit its application in validating gene function and molecular breeding of Chinese chestnut. The genetic transformation of Chinese chestnut will also provide a reference for other Castanea species that are not currently genetically transformed, including C. crenata, C. henryi, C. seguinii and $C$. pumilla, broadening its applications to plants, improving functional genomic research and genetic modification of Castanea germplasm.
Kanamycin is one of the most commonly used antibiotics to kill untransformed tissue in many genetic transformation processes (Mcgranahan et al. 1993; Seabra and Pais 1998; Yepes and Aldwinckle 1994; Sabbadini et al. 2019). The concentration of kanamycin differs among species, such as $100 \mathrm{mg} / \mathrm{L}$ for American pecans (Mcgranahan et al. 1993), $70 \mathrm{mg} / \mathrm{L}$ for grape (Sabbadini et al. 2019) and $150 \mathrm{mg} / \mathrm{L}$ for European chestnut (Seabra and Pais 1998). The $150 \mathrm{mg} / \mathrm{L}$ kanamycin used in the genetic transformation of European chestnut suppressed the regeneration of $98 \%$ of non-transformed somatic embryos (Seabra and Pais 1998). European chestnut showed low susceptibility to kanamycin, which may be due to the presence of endogenous nonspecific kanamycin phosphotransferase activity (Yepes and Aldwinckle 1994). In our study, $180 \mathrm{mg} / \mathrm{L}$ kanamycin completely inhibited the proliferation of embryogenic callus of Chinese chestnut, and we speculate that the low susceptibility of Chinese chestnut to kanamycin may be caused by the same reason as in European chestnut.

In the present study, the shoot regeneration rate was very low, and only two transgenic shoots were obtained. In addition, the two transgenic shoots showed a heterogeneous pattern of GFP detection (Fig. 4k, 1), which were considered to be chimeras. The low transgenic regeneration rate of Chinese chestnut embryogenic calli presumably was because of addition of kanamycin, which reduced shoot regeneration capacity (Sabbadini et al. 2019). In addition to antibiotics, the Agrobacterium strain may affect the emergence of shoots. In our study, the genetic transformation using AGL1 strain led to the regeneration of transgenic shoots, indicating that AGL1 might be more suitable for genetic transformation of Chinese chestnut compared with GV3101. Agrobacterium strains GV3101 and AGL1 not only have different chromosomal backgrounds but also different vir helper plasmids with different levels of activating potential (Mayavan et al. 2015), which may explain the stronger capability of AGL1 to infect Chinese chestnut. AGL1 has been successfully used for the genetic transformation of many plants, such as American chestnut, barley, sorghum, tomato, and sugarcane (Andrade et al. 2009; Hisano et al. 2017; Do et al. 2016; Chetty et al. 2013; Mayavan et al. 2015).

The genetic transformation system of Chinese chestnut can accelerate the molecular breeding of Chinese chestnut, thus hastening the creation of new germplasm. First, Chinese chestnuts do not produce flowers or fruits during the long juvenile phase spanning several years (Hackett et al. 1985; Martin-Trillo and Martinez-Zapater 2002; Poethig 1990). Genetic transformation may solve this problem. The blueberry FLOWERING LOCUS T gene $(V c F T)$ was transferred into petunia, which resulted in early flowering in transgenic plants (Lin et al. 2019). Besides, the disease resistance of Chinese chestnut might be improved by transgenic technology. Although Chinese 

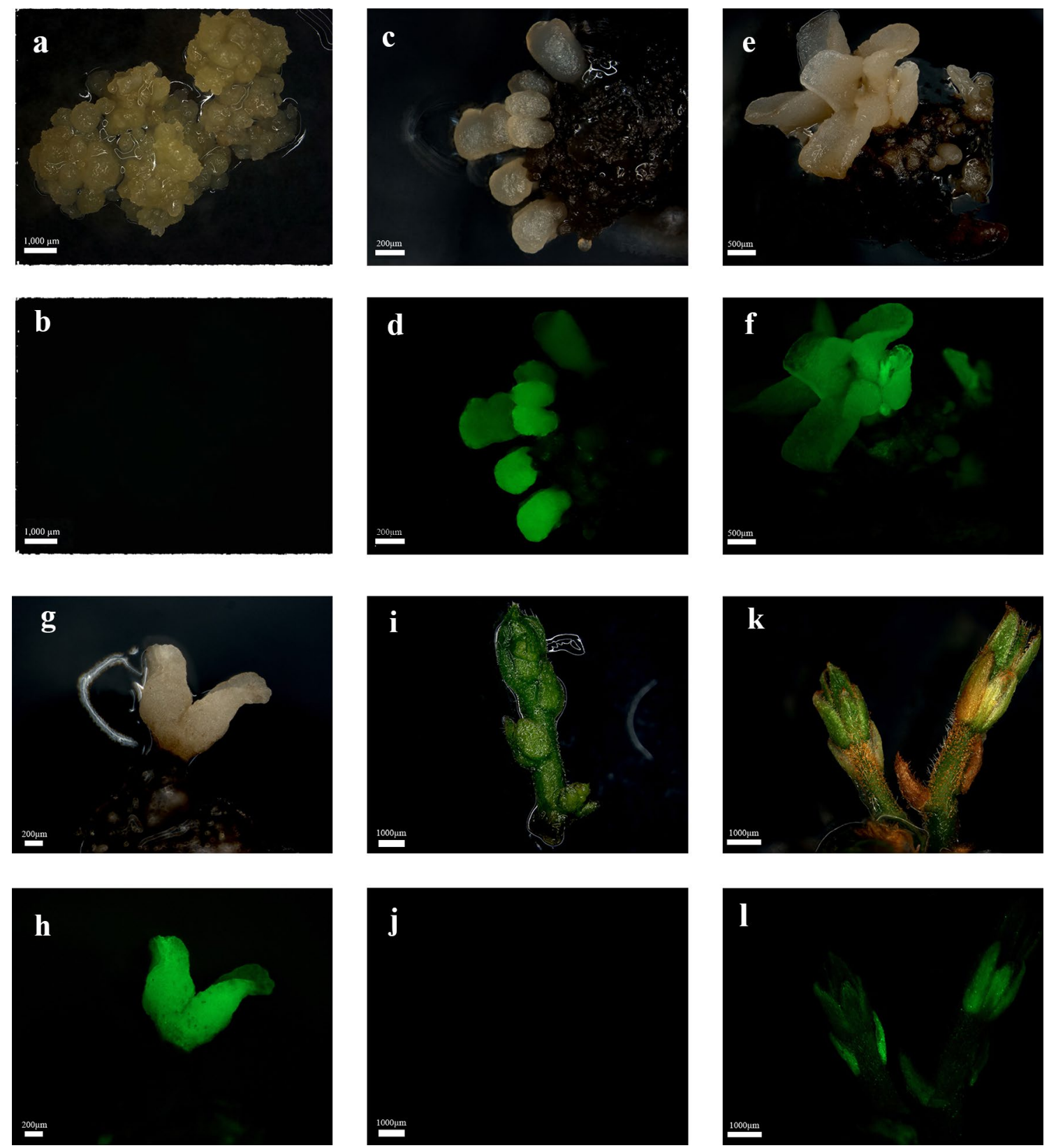

Fig. 4 Fluorescence observation of somatic embryos of Chinese chestnut under fluorescent microscopy. a, b Represent non-transformed somatic embryos. $\mathbf{c}-\mathbf{h}$ Represent transformed somatic embryos. b, d, f and $\mathbf{h}$ were observed under UV light. a, c, e and $\mathbf{g}$

chestnut exhibits higher resistance than European chestnut and American chestnut, not all Chinese chestnut trees have a strong ability to resist pathogens, and some cultivars are susceptible to fungal or viral infection. Genetic transformation has become a powerful tool for European chestnut and American chestnut in terms of improving the resistance and tolerance of ink disease (Corredoira et al. 2012) and blight disease (Newhouse et al. 2014), which provide ideas for increasing resistance to disease were observed under white light. $\mathbf{k}$ and $\mathbf{l}$ represent transformed shoots of Chinese chestnut. $\mathbf{i}$ and $\mathbf{j}$ represent non-transformed shoots of Chinese chestnut. $\mathbf{i}$ and $\mathbf{k}$ were observed under white light. $\mathbf{j}$ and $\mathbf{l}$ were observed under UV light

in Chinese chestnut. Moreover, the genetic transformation can be used to modify the plant architecture of Chinese chestnut. The height of the cultivars is more than three meters, hampering pruning and nut harvesting. Thus, the creation of dwarf or semi-dwarf varieties and rootstocks will be one of most important breeding objectives for Chinese chestnut. Indeed, dwarf-related genes, including ipt, rolA, rolB, rolC and rolD, have been transferred into apple trees, and dwarf varieties were obtained (Xue et al. 2008). 
Fig. 5 PCR detection of target genes at the DNA level. a PCR detection of the EGFP gene at the DNA level. b PCR detection of the kanamycin gene at the DNA level. M, DL2000 marker. $\mathrm{P}$, positive control (plasmid). U, negative control (non-transgenic sample). W, water. 1-7 represent transgenic embryogenic callus

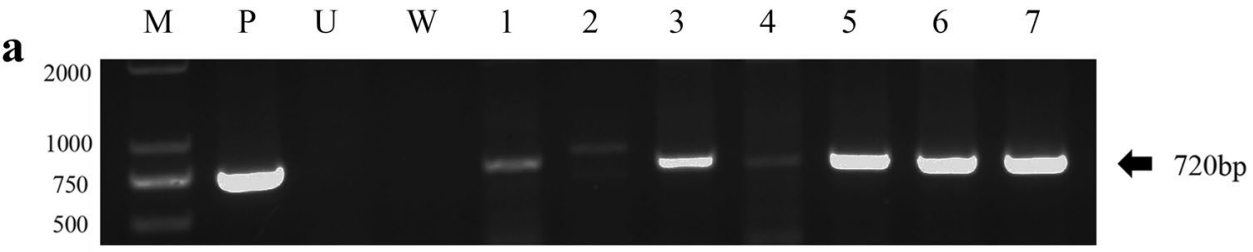

b

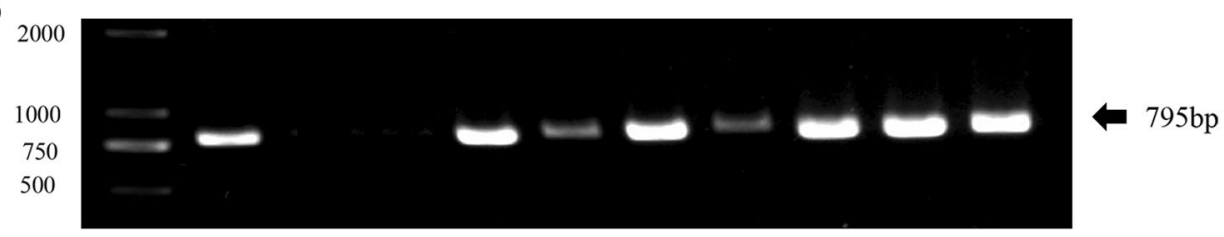

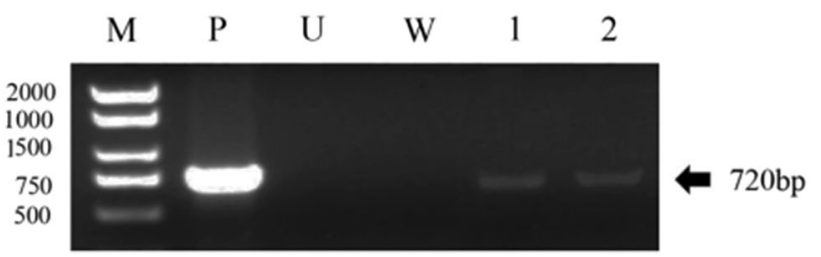

Fig. 6 PCR detection of the EGFP gene at the RNA level of transgenic shoots. M, DL2000+ marker. P, positive control (plasmid). U, negative control (non-transgenic sample). W, water. 1-2 represent transgenic shoot

These dwarf or semi-dwarf molecular breeding in apple may be applied to Chinese chestnut.

Acknowledgements This work was supported by the Importation and Development of High-Caliber Talents Project of Beijing Municipal Institutions (Grant No. CIT\&TCD20180317), the National Natural Science Foundation of China (Grant No. No.31672135), Beijing Natural Science Foundation (Grant No. No.KZ201710020012) and the National Key Research \& Development Program of China (Grant No. 2018YFD1000605).

Author contributions Study conception and design-LQ, QC; performed experiments-ZS, XL (Xiao Li), WZ, YG, JS, JY; analysis of data-ZS, XL (Xiao Li), WZ; drafting of manuscript-ZS, WZ, QC; improvement of the manuscript-ZS, XL (Xiaowei Li), QC; final approval of the version to be published-LQ, QC, YX, XL (Xiaowei Li), KF, QZ.

\section{Compliance with ethical standards}

Conflict of interest The authors declare that the research has no conflict of interest.

Open Access This article is distributed under the terms of the Creative Commons Attribution 4.0 International License (http://creativeco mmons.org/licenses/by/4.0/), which permits unrestricted use, distribution, and reproduction in any medium, provided you give appropriate credit to the original author(s) and the source, provide a link to the Creative Commons license, and indicate if changes were made.

\section{References}

Andrade GM, Nairn CJ, Le HT, Merkle SA (2009) Sexually mature transgenic American chestnut trees via embryogenic suspensionbased transformation. Plant Cell Rep 28:1385-1397. https://doi. org/10.1007/s00299-009-0738-7

Cheng L, Su S, Qin L, Yin W (2005) Extraction of DNA and estabilishment of AFLP techniques in leaves of Castanea mollissima Blume. J Beijing Agric Coll 2:5-9

Chen Y, Rivlin A, Lange A, Ye X, Vaghchhipawala Z, Eisinger E, Dersch E, Paris M, Martinell B, Wan Y (2014) High throughput Agrobacterium tumefaciens-mediated germline transformation of mechanically isolated meristem explants of cotton (Gossypium hirsutum L.). Plant Cell Rep 33:153-164. https://doi.org/10.1007/ s00299-013-1519-x

Chetty VJ, Ceballos N, Garcia D, Narvaez-Vasquez J, Lopez W, Orozco-Cardenas ML (2013) Evaluation of four Agrobacterium tumefaciens strains for the genetic transformation of tomato (Solanum lycopersicum L.)cultivar Micro-Tom. Plant Cell Rep 32:239-247. https://doi.org/10.1007/s00299-012-1358-1

Corredoira E, Montenegro D, San-Jose MC, Vieitez AM, Ballester A (2004) Agrobacterium-mediated transformation of European chestnut embryogenic cultures. Plant Cell Rep 23(5):311-318. https://doi.org/10.1007/s00299-004-0804-0

Corredoira E, San-José MC, Vieitez AM, Ballester A (2007) Improving genetic transformation of European chestnut and cryopreservation of transgenic lines. Plant Cell Tissue Organ Cult 91(3):281-288

Corredoira E, Valladares S, Allona I, Aragoncillo C, Vieitez AM, Ballester A (2012) Genetic transformation of European chestnut somatic embryos with a native thaumatin-like protein (CsTL1) gene isolated from Castanea sativa seeds. Tree Physiol 32(11):1389-1402

Do PT, Lee H, Mookkan M, Folk WR, Zhang ZJ (2016) Rapid and efficient Agrobacterium-mediated transformation of sorghum (Sorghum bicolor) employing standard binary vectors and bar gene as a selectable marker. Plant Cell Rep 35(10):2065-2076. https://doi.org/10.1007/s00299-016-2019-6

FAO. Food and Agriculture Organization of the United Nations. FAOSTAT Statistics Database 2017. http://www.fao.org/faostat/ en/\#home. Accessed 17 May 2019

Hackett WP (1985) Juvenility, maturation, and rejuvenility in woody plants. Hortic Rev 7:109-155

Hebard FV (2006) The backcross breeding program of the American chestnut foundation. Am Chestnut Found 19:55-77

Hisano H, Meints B, Moscou MJ, Cistue L, Echavarri B, Sato K, Hayes PM (2017) Selection of transformation-efficient barley genotypes based on TFA (transformation amenability) haplotype and higher 
resolution mapping of the TFA loci. Plant Cell Rep 36(4):611620. https://doi.org/10.1007/s00299-017-2107-2

Lazo GR, Stein PA, Ludwig RA (1991) A DNA transformation-competent Arabidopsis genomic library in Agrobacterium. Biotechnology 9(10):963-967

Lin T, Chen Q, Wichenheiser RZ, Song G (2019) Constitutive expression of a blueberry FLOWERING LOCUS T gene hastens petunia plant flowering. Sci Hortic 253:376-381. https://doi. org/10.1016/j.scienta.2019.04.051

Liu YR, Cen HF, Yan JP, Zhang YW, Zhang WJ (2015) Inside out: high-efficiency plant regeneration and Agrobacterium-mediated transformation of upland and lowland switchgrass cultivars. Plant Cell Rep 34(7):1099-1108. https://doi.org/10.1007/s0029 9-015-1769-x

Lloyd G, McCown B (1980) Commercially feasible micro-propagation of Mountain Laurel, Kalmia latifolia, by use ofshoot tip culture. Comb Proc Int Plant Propagators Soc 30:421-427

Lu D, Wei W, Zhou W et al (2017) Establishment of a somatic embryo regeneration system and expression analysis of somatic embryogenesis-related genes in Chinese chestnut (Castanea mollissima Blume). Plant Cell Tissue Organ Cult 130(3):601-616

Martin-Trillo M, Martinez-Zapater JM (2002) Growing up fast: manipulating the generation time of trees. Curr Opin Biotechnol 13(2):151-155

Mayavan S, Subramanyam K, Arun M, Rajesh M, Kapil Dev G, Sivanandhan G, Jaganath B, Manickavasagam M, Selvaraj N, Ganapathi A (2013) Agrobacterium tumefaciens-mediated in planta seed transformation strategy in sugarcane. Plant Cell Rep 32:1557-1574. https://doi.org/10.1007/s00299-013-1467-5

Mayavan S, Subramanyam K, Jaganath B, Sathish D, Manickavasagam M, Ganapathi A (2015) Agrobacterium-mediated in planta genetic transformation of sugarcane setts. Plant Cell Rep 34(10):18351848. https://doi.org/10.1007/s00299-015-1831-8

Maynard CA, McGuigan LD, Oakes AD et al (2015) Chestnut, American (Castanea dentata (Marsh.) Borkh.). Methods Mol Biol 1224:143-161

Mcgranahan GH, Leslie CA, Dandekar AM, Uratsu SL, Yates IE (1993) Transformation of pecan and regeneration of transgenic plants. Plant Cell Rep 12(11):634-638

Merkle SA, Wiecko AT, Watson-Pauley BA (1991) Somaticembryogenesis in American chestnut. Can J For Res 21:1698-1701

Merkle SA, Carraway DT, Wilde HD (1994) Somatic embryogenesis and gene transfer in American chestnut. Am Chestnut Found $8: 29-33$

Miller AC, Woeste KE, Anagnostakis SL, Jacobs DF (2014) Exploration of a rare population of Chinese chestnut in North America:stand dynamics, health and genetic relationships. AoB Plants 6:11-15. https://doi.org/10.1093/aobpla/plu065

Newhouse AE, Polin-Mcguigan LD, Baier KA, Valletta KER, Rottmann WH, Tschaplinski TJ, Maynard CA, Powell WA (2014)
Transgenic American chestnuts show enhanced blight resistance and transmit the trait to T1 progeny. Plant Sci 228:88-97

Nitsch JP, Nitsch C (1969) Haploid plants from pollen grains. Science 163:85-87

Palla KJ, Pijut PM (2015) Agrobacterium-mediated genetic transformation of Fraxinus americana hypocotyls. Plant Cell Tissue Organ Cult 120(2):631-641

Poethig RS (1990) Phase change and the regulation of shoot morphogenesis in plants. Science (New York, N.Y.) 250(4983):923-930. https://doi.org/10.1126/science.250.4983.923

Polin LD, Liang H, Rothrock RE, Nishii M, Diehl DL, Newhouse AE (2006) Agrobacterium-mediated transformation of American chestnut (Castanea dentata (Marsh.) Borkh.) somatic embryos. Plant Cell Tissue Organ Cult 84(1):69-78. https://doi.org/10.1007/ s11240-005-9002-1

Sabbadini S, Capriotti L, Molesini B, Pandolfini T, Navacchi O, Limera C, Ricci A, Mezzetti B (2019) Comparison of regeneration capacity and Agrobacterium-mediated cell transformation efficiency of different cultivars and rootstocks of Vitis spp. via organogenesis. Sci Rep 9(1):582. https://doi.org/10.1038/s41598-018-37335-7

Sambrook J, Fritsch EF, Maniatis T (1989) Molecular cloning: a laboratory manual, 2nd edn. Cold Spring Harbor Laboratory Press, Cold Spring Harbor

Seabra RC, Pais MS (1998) Genetic transformation of European chestnut. Plant Cell Rep 17:177-182

Vidal N, Mallon R, Valladares S, Meijomin AM, Vieitez AM (2010) Regeneration of transgenic plants by Agrobacterium-mediated transformation of somatic embryos of juvenile and mature Quercus robur. Plant Cell Rep 29:1411-1422. https://doi. org/10.1007/s00299-010-0931-8

Wu E, Zhao ZY (2017) Agrobacterium-mediated sorghum transformation. Methods Mol Biol (Clifton, N.J.) 1669:355-364. https://doi. org/10.1007/978-1-4939-7286-9-26

Xue Z, Anna H, Margareta W (2008) Intron splicing in 5' untranslated region of the rolA transcript in transgenic apple. Plant Physiol 165:544-552

Yepes LM, Aldwinckle HS (1994) Factors that affect leaf regeneration efficiency in apple, and effect of antibiotics in morphogenesis. Plant Cell Tissue Organ Cult 37:257-269

Zhang B, Newhouse A, Mcguigan L, Maynard C, Powell W (2011) Agrobacterium-mediated co-transformation of American chestnut (Castanea dentata) somatic embryos with a wheat oxalate oxidase gene. BMC Proc 5(7):1-3

Publisher's Note Springer Nature remains neutral with regard to jurisdictional claims in published maps and institutional affiliations.

\section{Affiliations}

\section{Zhi-lin Sun ${ }^{2} \cdot$ Xiao Li $^{2} \cdot$ Wan Zhou ${ }^{2} \cdot$ Jun-di Yan ${ }^{2} \cdot$ Yue-rong Gao ${ }^{2} \cdot$ Xiao-wei $\mathrm{Li}^{2} \cdot \mathrm{Jia}$-chen Sun ${ }^{2} \cdot \mathrm{Ke}$-feng Fang ${ }^{3,4}$. Qing Zhang ${ }^{2} \cdot$ Yu Xing ${ }^{1,2} \cdot$ Ling Qin ${ }^{1,2} \cdot$ Qing-qin Cao ${ }^{1,2}$}

1 Beijing Advanced Innovation Center for Tree Breeding by Molecular Design, Beijing University of Agriculture, Beijing 102206, China

2 Beijing Key Laboratory for Agricultural Application and New Technique, Beijing 102206, China
3 Beijing Collaborative Innovation Center for Eco-environmental Improvement with Forestry and Fruit Trees, Beijing 102206, China

4 College of Landscape Architecture, Beijing University of Agriculture, Beijing 102206, China 